\title{
Mindset Wanita Pengusaha Sukses
}

\author{
Rizki Kusumadewi Saputri, ${ }^{1,2}$, Fathul Himam ${ }^{3}$
}

Fakultas Psikologi Universitas Gadjah Mada

\begin{abstract}
Many evidents show that women play important role in economic development of a region and a country. Any obstacles in business do not always inhibit them to be successful entrepreneur. This research was conducted to understand the nature of mindset owned by successful business women. The approach used was phenomenology to four respondents, who were female entrepreneurs. Data were collected by in-depth interview with them concerning food, drink, fashion and retails that were obtained through networking. The data were analyzed involving several main processes, namely epoche, phenomenological reduction, imaginative variation and synthesis of meaning and essences. The credibility of the results was obtained through member checking. The results showed that these women's mindset consisted of cognitive component, metacognitive and motivation. The internal structure within the mindset were built of interdependence, differentiation, spiritualism and learning.
\end{abstract}

Keywords: women's limitation, entrepreneurship, mindset, successful female entrepreneur

Abstrak. Kendala-kendala wanita dalam berwirausaha tidak selalu menjadi penghalang bagi wanita pengusaha untuk sukses. Terbukti saat ini wanita berperan penting dalam pembangunan ekonomi daerah dan negara. Penelitian ini dilakukan untuk memahami hakikat mindset yang dimiliki wanita pengusaha sukses. Penelitian ini menggunakan pendekatan fenomenologi. Data diperoleh melalui wawancara mendalam terhadap empat wanita pengusaha sukses dalam bidang makanan, minuman, fashion dan ritel yang diperoleh melalui networking. Data hasil penelitian dianalisis dengan melibatkan beberapa proses inti, yaitu: epoche, phenomenological reduction, imaginatif variation serta synthesis of meaning and essences. Kredibilitas hasil penelitian menggunakan member checking. Hasil penelitian menunjukkan bahwa mindset yang dimiliki wanita pengusaha mengandung kompenen kognitif, metakognitif dan motivasi. Struktur internal yang terkandung di dalamnya adalah interdependensi, diferensiasi, spiritualisme dan learning.

Kata kunci: keterbatasan wanita, kewirausahaan, mindset, wanita pengusaha sukses

Jumlah wanita pengusaha di Indonesia hingga tahun 2004 berdasarkan data Badan Pusat Statistik (2014) sebanyak 5.590 .638 orang. Mayoritas wanita pengusaha berada di wilayah Jawa dan Bali, dengan jumlah 4.030.236 orang. Jumlah tersebut menandakan bahwa tren wanita

\footnotetext{
${ }^{1}$ Korespondensi mengenai artikel ini dapat dilakukan melalui: saputri.rizki@gmail.com

${ }^{2}$ Owner Online Shop Kusumadewi Ethnic,Yogyakarta

3 Atau melalui: fhimam@ugm.ac.id
}

pengusaha mengalami peningkatan dari tahun ke tahun menyaingi jumlah pria pengusaha. Tren wanita pengusaha meningkat sebesar 2,05\% dari 5,86\% pada tahun 2009 menjadi 7,91\% pada tahun 2012. Tren wanita pengusaha $7,91 \%$ pada tahun 2012 berhasil melebihi tren pria pengusaha $7,80 \%$ sebesar $0,11 \%$.

Proses kewirausahaan antara pria dan wanita tidak berbeda, namun dalam praktiknya wanita lebih banyak mengalami 
kendala dalam berwirausaha (Tambunan, 2009). Berdasarkan riset-riset di Bangladesh, India, Indonesia, dan Afrika Selatan didapati bahwa kendala-kendala wanita dalam berwirausaha adalah; (1) Hukum, adat, tradisi, budaya dan agama (2) status perkawinan (3) pekerjaan rumah tangga yang berat (4) keterbatasan pendidikan, pengetahuan dan informasi (5) Keterbatasan dana sebagai modal dan akses kredit (6) jaringan kelembagaan yang kurang memadai (Ahamad \& Moudud-UI-Hug, 2013; Bhardwaj, 2008; Bruni, Gherrardi \& Poggio, 2004; Derera, Chitakunye \& O'Naill, 2014; Ganesan, Kaur \& Maheshwari, 2002; Pawan \& Rajesh, 2009; Ragoobur \& Kasseeah, 2012; Sharma, 2013; Tambunan, 2008; Tambunan, 2009). Kanungo (2003) menambahkan bahwa keterbatasan wanita pengusaha untuk memulai usaha adalah; (1) hambatan pengambilan risiko karena wanita kurang tegas dan percaya diri (2) status wanita dalam struktur sosial membuat wanita tergantung pada pria (suami, ayah dan keluarga) (3) kurangnya akses pendidikan dan pelatihan bagi wanita, dan (4) sulitnya akses dana dan kredit bagi wanita.

Kendala-kendala tersebut, khususnya di Indonesia menjadi dasar bagi wanita dalam pemilihan bidang usaha. Wanita cenderung menggeluti usaha yang tidak membutuhkan keterampilan tinggi dan modal yang besar, menggunakan teknologi sederhana dan mudah dikelola. Berdasarkan hal tersebut, mayoritas wanita bergelut dalam bisnis makanan dan minuman, industri tembakau, tekstil, garmen dan kulit, kerajinan dan produk mineral non logam. Hal tersebut berbeda dengan pria yang mayoritas bergelut dalam bisnis seperti hotel, restoran dan pertokoan (Tambunan, 2009). Hisrich (2005) menambahkan bahwa wanita pengusaha memulai bisnis dalam hal ritel, berhubungan dengan masyarakat atau jasa pendidikan sedangkan pria pengusaha cenderung memasuki bisnis manufaktur, konstruksi dan teknologi. Pengusaha wanita cenderung memiliki bisnis kecil dengan pendapatan bersih yang rendah.

Bermodal keterampilan dan dana yang minim serta teknologi yang sederhana, wanita pengusaha terbukti dapat meraih kesuksesan. Berdasarkan riset-riset (Buttner \& Moore, 1997; Dhaliwal, 2000; Farrington, 2006; Hailemariam \& Kroon, 2014; Kanungo, 2003; Masuo, Fong \& Yanagida, 2001; Paige \& Littrel 2002) definisi kesuksesan secara umum dan hakikat kesuksesan dari wanita pengusaha tidak berbeda. Hakikat sukses pada wanita pengusaha dapat dilihat berdasarkan dua kriteria, yaitu kriteria instrinsik dan ekstrinsik. Sukses berdasarkan kriteria instrinsik meliputi; (1) kemandirian (2) dapat mengendalikan masa depan diri sendiri (3) menjadi bos bagi diri sendiri (4) berprestasi. Sukses berdasarkan kriteria ekstrinsik meliputi (1) pengembalian aset (2) penjualan meningkat (3) keuntungan meningkat (4) peningkatan jumlah karyawan (5) dapat membahagiakan karyawan dan pelanggan (6) pengembangan bisnis, dan (7) dapat mensejahterakan keluarga.

Kesuksesan dapat dicapai tergantung seberapa cerdas mengamati dan menafsirkan perubahan (Gupta \& Govindarajan, 2002). Salah satu dasar utama yang diperlukan untuk membangun kecerdasan tersebut adalah menciptakan mindset (Story \& Barbuto, 2011; Gupta \& Govindarajan, 2002). Berdasarkan riset-riset (Ang \& Dyne, 2008; Fujitta, Gollwitzer \& Oettigen, 2007; Gupta \& Govindarajan, 2002; Pikens, 2005; Story \& Barbuto, 2011) didapati bahwa mindset merupakan konsep pada psikologi kognitif yang berfokus bagaimana seseorang memahami dunia, beradaptasi, berinteraksi dan berperilaku 
sesuai dengan lingkungan dan budaya yang baru. Mindset penting dimiliki oleh seseorang yang berwirausaha agar mampu berintegrasi (ability) dan terbuka (openness) terhadap market dan culture yang berbeda. Selain itu, seorang yang berwirausaha harus menumbuhkembangkan mindset kewirausahaan.

Berdasarkan temuan dari berbagai riset ilmiah (Ang \& Dyne, 2003; Fujitta, Gollwitzer \& Oettigen, 2007; Gupta \& Govindarajan, 2002; Pikens, 2005; Story \& Barbuto, 2011) didapati bahwa mindset sebagai kunci mencapai sukses tidak hanya terdiri atas komponen kognitif, tetapi mengandung komponen motivasional dan metakognitif atau perilaku sebagai realisasi orientasi untuk selektif terhadap informasi guna mencapai tujuan, yaitu kesuksesan.

Mindset sebagai realisasi orientasi untuk memprediksi perilaku guna mencapai tujuan, yaitu kesuksesan berdasarkan riset (Alam, Jani \& Omar, 2011; Ali \& Ali, 2013; Ang \& Dyne, 2008; Brownson, 2013; Farrington, 2006; Fujitta, Gollwitzer \& Oettigen, 2007; Gupta dan Govindarajan, 2002; Hoyos, 2011; Huargn, 2012; Javadian \& Sigh, 2012; Lydianingtyas, Zain, Solimun \& Rahayu, 2011; Munshi, Munshi \& Singh, 2011; Story \& Barbuto, 2011) di Wilayah Selatan Malaysia, Indonesia, India dan Poerto Rico dipengaruhi oleh dua faktor, yaitu faktor personal dan faktor situasional.

Faktor personal adalah ketika perilaku dipengaruhi oleh kepribadian seseorang. Faktor personal dapat berupa motif (drive), intelektual, ketrampilan, dan tingkat aktivitas. Tingkat aktivitas yang dimaksud adalah orang yang sangat aktif cenderung bertindak dengan cara yang konsisten dengan sikapnya, sedangkan individu yang apatis yang acuh tak acuh terhadap lingkungannya cenderung tidak bertindak kuat untuk mendapatkan tujuannya (Wicker, 1969). Hasil riset lainnya menambahkan bahwa motivasi, persepsi, self efficacy dan pengambilan risiko serta penciptaan mindset kewirausahaan juga merupakan bagian dari faktor personal yang mampu memfasilitasi terciptanya mindset sukses.

Di sisi lain, faktor situasional adalah ketika perilaku seseorang dipengaruhi oleh situasi lingkungan sekitarnya. Situasional dapat berupa kehadiran orang lain, perilaku norma atau aturan dan peristiwaperistiwa tidak terduga (Wicker, 1969). Hasil riset lainnya menambahkan bahwa ikatan sosial, dukungan keluarga dan kebijakan pemerintah juga merupakan bagian dari faktor situasional yang memfasilitasi terciptanya mindset sukses. Hasil-hasil riset tersebut menyatakan bahwa faktor personal berdampak positif dan lebih signifikan mewujudkan kesuksesan (Alam, Jani \& Omar, 2011; Ali \& Ali, 2013; Lydianingtyas, Zain, Solimun \& Rahayu, 2011; Javadian \& Sigh, 2012, Wicker, 1969).

Pemberian kesempatan yang setara bagi wanita dan pria menjadi pengusaha akan berefek positif dalam pengurangan kemiskinan (Tambunan, 2009). Terbukti, saat ini wanita pengusaha juga memainkan peran sangat penting dalam membangun dan menstabilkan perekonomian, tidak hanya perekonomian daerah tetapi juga perekomian negara (Ali \& Ali, 2013; Munshi, Munshi \& Singh, 2011; Tambunan, 2009). Wanita pengusaha berkontribusi cukup besar pada perekonomian dengan lebih dari $25 \%$ jenis bisnis.

Berangkat dari fenomena di atas, tujuan dari penelitian ini adalah untuk memahami hakikat mindset sukses dari wanita pengusaha. Sehingga, pertanyaan penelitian ini adalah; (1) Bagaimana hakikat mindset sukses wanita pengusaha 
terhadap keberhasilan usahanya? dan (2) Dimensi-dimensi apakah yang terkandung dalam struktur internal mindset yang berfungsi memfasilitasi keberhasilan wanita dalam berwirausaha?

\section{Metode}

Penelitian ini menggunakan pendekatan fenomenologi (Moustakas, 1994). Data diperoleh dengan melakukan wawancara mendalam terhadap empat wanita pengusaha sukses dalam bidang makanan, minuman, fashion dan ritel. Adapun kriteria sukses pada wanita pengusaha meliputi; (1) memiliki karyawan yang jumlahnya terus meningkat (2) memiliki outlet, cabang atau bisnis di bidang lain (3) memiliki banyak pelanggan yang salah satu cirinya adalah outlet selalu ramai pengunjung (4) dikenal masyarakat (5) melakukan inovasi terhadap penjualan produk atau jasa sehingga jumlah produk meningkat dan berkembang (6) berprestasi di bidangnya, seperti mendapatkan penghargaan sebagai wanita pengusaha tersukses, penghargaan sebagai wanita pengusaha dengan omset tinggi, penghargaan sebagai wanita pengusaha yang kreatif dan inovatif dan penghargaan lainnya. Responden tersebut diperoleh melalui networking (Davis, Lachlan \& Gallardo, 2009). Data hasil penelitian dianalisis dengan melibatkan beberapa proses inti, yaitu: epoche, phenomenological reduction, imaginatif variation serta synthesis of meaning and essences. Kredibilitas hasil penelitian menggunakan member checking (Moustakas, 1994).

\section{H a s i 1}

Usaha yang digeluti wanita pengusaha dimulai dari keinginan. Keinginan tersebut kemudian diwujudkan dalam kegiatan usaha. Berproses menjalani kegiatan usaha, faktor-faktor eksternal sangat berperan penting dalam membantu wanita pengusaha menciptakan struktur internal mindset wirausaha. Mindset tersebut diwujudkan dalam perilaku dan berperan sebagai strategi yang tepat untuk mencapai kesuksesan. Mindset tersebut terdiri dari empat dimensi: (1) interdependensi (2) spiritualisme (3) diferensiasi (4) learning. Kesuksesan yang dimaksud oleh wanita pengusaha adalah kebahagiaan, dapat membahagiakan diri sendiri dan orang lain. Lebih detilnya, hasil penelitian ini dijabarkan melalui analisis tematik.

\section{Intedependensi}

Berdasarkan wawancara terhadap R1, R2, R3 dan R4, interdependensi merupakan proses menyatukan kekurangan satu sama lain. Kebutuhan tidak akan terpenuhi tanpa produksi orang lain. Interdependensi horizontal merupakan kerja sama dan ketergantungan sesama manusia. Wujud mindset interdependensi yang muncul adalah kerja sama antar rekan kerja seperti pemerintah dan keluarga.

“...sebenernya trus aku ga bisa berdiri sendiri kan. Jadinya aku harus keja sama dengan pemerintah. Nah kalo aku ngembangin jamu ga didukung sama pemerintah njuk gimana. Haaaa orangorang bule itu disana malah udah punya lahan sendiri lho, lahan buat nanem tho di bali. Di bali tu udah banyak. Disana mreka udah punya lahan organik" (W1.R1.23Juli14.347-353)

Terlihat bahwa pada R2 dan R4 dana sebagai modal usaha mereka dapatkan dari orang tua maupun mertua. Hal tersebut dilakukan karena wanita pengusaha takut terjerat bunga bank. Keuntungan modal dari orang tua dapat diangsur dan juga tidak berbunga. 
“...saya mulainya dari warung kecil mbak, ga langsung besar gini ya. Jadi itu tanpa pelayan, dengan modal 250rb, atau senilai $100 \mathrm{gr}$ emas. Itu dipinjam dari ibu saya $175 \mathrm{rb}$ yang $75 \mathrm{rb}$ karnakan baru menikah, jadi masih banyak sangu nah itu dijadikan modal untuk modal awal gitu" (W1R4.8Agustus14.3-11)

“...tanahnya itu dari orang tua seluas 35 meter. Lebar depan itu hanya 3 meter terus bangunannya waktu bangun bangunan $3 \times 5$ meter itu yang bangunkan mertua saya. Jadi kedua orang tua membantu" (W1R4.8Agustus14.77-85)

“...udah ada usaha di Bengkulu. Jadi aku bareng bareng. Itu juga pinjem uang orang tua itu yang dibengkulu, buat bangunnya doang. Nanti diganti perlahan setelah itu jalan. Jadi pembayaran sewa tempat itu. sama aja nyewa juga jatohnya. Cuma itu jadi milik pribadi nyewanya. Gitu paling" (R1W3.22Juli14.558-543)

“...pengusaha itu kan kadang-kadang kepikiran ya buat ngutang bank, tapi kalo aku kalo bisa mengurangi itu. Modal sendiri dan investor. Mengurangi pinjam bank. Karna kalo pinjam bank kan bunganya apalah. Itu kan serem"

(W1R1.23Juli14.508-513)

\section{Spiritualisme}

Berdasarkan wawancara terhadap R1, R2, R3 dan R4, spriritualisme merupakan karakter rohani dalam diri. Mindset spiritualisme memberikan arti usaha sebagai ibadah. Ibadah merupakan perbuatan atau pernyataan bakti kepada Allah SWT. Dua kunci utama menjalankan usaha dengan niat ibadah yaitu kesabaran dan keikhlasan. Menunaikan tanggungjawab bukan hanya kepada rekan usaha, karyawan, customer dan supplier, tetapi juga kepada Allah SWT. “...jadi ga sekedar okelah 2,5\% gitu, tapi kalo ga terlibat itu rasanya kurang. Mungkin ada orang yang ga perlu terlibat kegiatan sosial yang penting duitnya sampe kadang ada juga yang dititipkan dari rumah zakat dan sebagainya. Kalo aku enggak, kalo aku maunya harus langsung ke orang ini. Karna memang prinsipnya beda ya" (W3R1.14Agustus 14.275-280)

“...tapi kebetulan kok ya saya juga ikhlas memberikan rumah saya yang mau saya jual coba. Tidak saya berikan sih tapi menempati, meminjamkan gitu ya. Trus setelah saya terjun kok saya menikmati. Saya bahagia dengan anak asuh saya. Dhuafa, yang yatim. Ditengah tengah saya kunjungi di rumah saya itu kok saya seneng ya. Jadi ada kebahagiaan tersendiri" (W2R4.16Agustus14.595-598)

“...jadi kalo untuk membantu itu program dari kita ya. Eee kita punya uangkan bukan milik kita. Kita bersedekah itu kan menurutku hukumnya wajib, menurutku. Jangan cuma kita yang merasakan enak, tapi orang juga" (W1R2.19Juli14.879883)

\section{Diferensiasi}

Berdasarkan wawancara terhadap R1, R2, R3 dan R4, diferensasi merupakan proses, cara, perbuatan membedakan dan pembedaan. Diferensiasi juga merupakan perkembangan, kebanyakan dari yang sederhana menjadi sulit, yang homogen menjadi heterogen. Wujud mindset diferensiasi terbagi dua yaitu inovasi dan pengembangan. Inovasi menekankan pada kualitas, pengembangan menekankan pada kuantitas.

\section{Inovasi}

Berdasarkan wawancara kepada R1, R2, R3 dan R4, inovasi sangat penting 
dalam usaha. Tanpa inovasi usaha tidak akan berjalan, sehingga inovasi ditanamkan sejak awal usaha. Tanpa keunikan, usaha yang dibangun akan tenggelam. Wujud mindset inovasi khas pada wanita pengusaha adalah mengutamakan kualitas pelayanan.

“...emang dari awal udah inovasi dari awal. Karna memang aku mencarinya deverensiasinya itu dari jamu yang ga biasa. Seperti itu, harus berbeda" (W3.R1.14Agustus14.362-364)

“...aku istilahnya pengen deverensiasi produk di cafeku itu bedanya dengan depot, bedanya dengan jamu jamu lain itu harus beda gitu lho. Karna yang aku jual itu kan uniknya. Uniknya apa, diferensiasinya apa, nah.. Masalah rasa. Gitu lho. Awalnya dari situ dulu"

(W2.R1.16Juli14.125-139).

“...ya namanya berbisnis ya, kalo kita ga punya keunikan sendiri ya tenggelam. Kalo aku gitu prinsipku"

(W2.R1.16Juli14.160-168).

“...mungkin ke pelayanan kita yang baik, gitu aja. Kalo untuk senyumnya. Makanya kalo posisi lebaran kemaren kan capek" (W2.R2.8Agustus14.530-532)

Menjaga kualitas produk yang akan dijual, dilakukan dengan melakukan proses seleksi produk khalal yang akan dipasarkan. Mereka mengecek setiap label MUI pada produk yang akan mereka pasarkan.

“...produknya saya jamin yang khalal, yang bagus. Saya jaga betul kualitas barang itu. saya tidak mau sembarangan menerima. Jadi saya mesti teliti. Saya harus melihat depkesnya sudah disahkan belum. Ha kalo sekarang kan ada MUInya, ini produknya siapa, jadi harus jelas dan bagus. Semua lewat saya. Saya belum mempercayakan ke karyawan. Selama ini saya merasa masih mampu, saya sendiri. Karyawan sebenernya udah banyak yang bisa sebetulnya, untuk order order udah karyawan. Tapi untuk pertama kali itu harus lewat saya"

(W1R4.8Agustus14.729-739)

Pengembangan

Berdasarkan wawancara terhadap R1, R2, R3 dan R4, pengembangan menekankan pada kuantitas seperti penambahan cabang dan usaha baru. Pengembangan usaha diperlihatkan dengan pembukaan cabang oleh wanita pengusaha. Mereka lebih nyaman mengembangkan cabang di daerahnya. Hal tersebut untuk mempermudah mereka melakukan controlling antar cabang.

“...sepertinya udah nyaman di Jogja itu soale deket ya to. Misale saya keliling kan ga jauh. Sudah nyaman semuanya jalan ya saya cuma cari cari yang di jogja aja dari pada ngurusnya repot. Sama sama cari keuntungan mbok yang dekat" (W1R4.8Agustus14.800-806)

Tidak hanya penambahan cabang, pengembangan usaha juga ditunjukkan dengan pembukaan usaha baru. Mereka cenderung mengembangkan usahanya pada pusat kecantikan dan pusat kebugaran. Hal ini merupakan bentuk kepedulian wanita pengusaha terhadap wanita. Mengembangkan usaha di bidang kecantikan dan kebugaran berhasil membuat ibu-ibu muda terikat dan juga membantu mengembangkan bisnis.

"...saya manjakan wanita dan ibu ibu muda untuk bisa belanja kosmetik lengkap kemudian juga ada salon untuk perawatan wajah, tubuh, rambut ya. Kemudian juga ada senam. Ruang senam di lantai $3 \mathrm{khu-}$ sus wanita. Biar ibu ibu muda itu terikat semua. Dari merawat tubuhnya, rambutnya, wajahnya, belanja untuk keluarganya 
di Pamella" (W1R4.8Agustus14.448455)

“...saya ga suka kalo ada wanita yang tidak merawat tubuhnya, wajahnya, badannya itu saya ga setuju. Jadi saya sukanya itu perempuan itu dikodratkan sebagai istri supaya menggembirakan suami, supaya suaminya itu seneng itu istri harus menjaga kesehatannya, kebersihannya, kecantikannya"

(W2.R4.16Agustus14.800-807)

“...saya peduli dengan itu. jadi semua wanita itu saya harapkan berpenampilan menarik gitu lho. Bukan menarik untuk orang lain, untuk suaminya"

(W2.R4.16Agustus14.810-812)

“...kalo sudah dirawat wajahnya ya harus kebugarannya. Itu ya harus dijaga. Ya saya sediakan senamnya. Dari bisnis to ini ya" (W2.R4.16Agustus14.822-824)

\section{Learning}

Berdasarkan wawancara terhadap R1, R2, R3 dan R4, learning merupakan proses belajar. Wanita pengusaha menganggap kendala usaha dan pengalaman gagal sebagai proses belajar yang membantu mereka beradaptasi dan bangkit kembali. Learning tidak hanya didapatkan melalui kendala usaha dan pengalaman gagal tetapi juga dari kesuksesan. Pengalaman sukses menjadi motivasi bagi wanita pengusaha. Perilaku yang membawa sukses cenderung akan berulang menjadi strategi jitu dalam proses usaha.

Wujud mindset learning khas wanita pengusaha yang Terlihat bahwa pada R1, R2, R3 dan R4 adalah menganggap gagal sebagai pelajaran karena belajar itu mahal. Wanita pengusaha juga selalu mensyukuri setiap keuntungan yang mereka dapat. Hal tersebut dikuatkan dengan keyakinan wanita pengusaha bahwa Allah akan memberikan yang terbaik untuk mereka.
Kegagalan dianggap wanita pengusaha sebagai cermin untuk melihat kembali perjuangan-perjuangan yang pernah mereka lakukan. Kegagalan juga mereka anggap sebagai proses adaptasi.

“...karna aku seneng aku ga' pernah menganggap itu sebagai kegagalan gitu lho. Disitu kita belajar bagaimana kita bisa apa ya istilahnya kita belajar bagaimana kita membangun apa memang belajar itu mahal" (W1.R2.19Juli14.649-653)

“...maksudnya oohh oke, kok sepi ya, yaudah gak apa. Misalnya baru satu juta gitu ya berarti itu keuntungannya belum punya kita. Belum buat kita. Next time insyaAllah akan ada yang lebih baik lagi. kalo aku sih selalu beranggapan yang seperti itu" (W1.R2.19Juli14.665-671)

“...ya sabar.. kan sedang dalam ujian. Sabar aja, mungkin bulan ini belum keuntungannya, bulan depan mungkin. Lagi dikasih cobaan. Usaha itu kan ga selalu naik, ada turunnya, iya kan"

(R3W1.22Juli14.529-531)

"...saya pasrah. Saya udah ga mampu saya lebih baik ga ikut tur ke bali. Saya keluar aja dari target"

(W2.R4.16Agustus14.161-168)

“...balik lagi ngelihat lagi perjuangan sebelumnya, tujuannya buat apa, visi misinya mau kemana. Balik lagi ngeliatnya kesitu, berkacanya kesitu. Aku kan mau ini mau ini"

(W3.R1.14Agustus14.453-456)

Berdasarkan hasil wawancara terhadap R1, R2, R3, dan R4, maka struktur internal mindset wanita pengusaha sukses dapat disimpulkan seperti tercantum pada Tabel 1.

Berdasarkan Tabel 1, dapat diketahui bahwa struktur internal mindset terdiri dari: (1) Interdependensi yang merupakan proses menyatukan kekurangan satu sama 
lain. Kebutuhan tidak akan terpenuhi tanpa produksi orang lain, saling tergantung sesama produsen. Wujud mindset interdependensi yang Terlihat bahwa adalah kerja sama, dan (2) Spiritualisme merupakan karakter rohani dalam diri. Mindset spiritualisme memberikan arti usaha sebagai ibadah. Ibadah merupakan perbuatan atau pernyataan bakti kepada Allah SWT. Dua kunci utama menjalankan usaha dengan niat ibadah yaitu kesabaran dan keikhlasan. Menunaikan tanggung jawab bukan hanya kepada rekan usaha, karyawan, customer dan supplier, tetapi juga kepada Allah SWT.

Wujud mindset spiritualisme adalah aktifnya para wanita pada kegiatan sosial (3) Diferensasi merupakan proses, cara, perbuatan membedakan dan pembedaan. Diferensiasi juga merupakan perkembangan, kebanyakan dari yang sederhana menjadi sulit, yang homogen menjadi heterogen. Wujud mindset diferensiasi terbagi dua yaitu inovasi dan pengembangan. Inovasi menekankan pada kualitas, pengembangan menekankan pada kuantitas (4) Learning merupakan adaptasi dari pengalaman gagal, kendala dan kesuksesan selama menjalani usaha.

Struktur internal mindset berperan penting dalam pengembangan usaha wanita pengusaha untuk meraih kesuksesan. Proses pengembangan usaha wanita pengusaha sukses terlihat pada Gambar 1 .

Gambar 1 menunjukkan bahwa mindset wanita pengusaha sukses terbentuk dari keinginan. Keinginan tersebut merupakan apa yang mereka suka dan apa yang mereka bisa. Setelah keinginan terbentuk, wanita pengusaha mewujudkan keinginan mereka melalui wirausaha dalam bidang food and beverage, fashion dan ritel dan kemudian berproses untuk terus berkembang.

Berproses menjalani kegiatan usaha, faktor-faktor eksternal sangat berperan penting dalam membantu wanita pengusaha menciptakan struktur internal mindset wirausaha. Mindset tersebut diwujudkan dalam perilaku dan berperan sebagai strategi jitu untuk mencapai kesuksesan. Mindset tersebut saling berhubungan satu sama lain. mindset learning yang terbentuk dari pengalaman gagal dan sukses akan membantu wanita pengusaha dalam beradaptasi. Kegagalan usaha diterima dengan ikhlas dan kesuksesan diimbangi dengan kegiatan-kegiatan sosial.

Selain ikut serta dalam kegiatankegiatan sosial, proses pengembangan usaha tidak lepas dari kerja sama dengan berbagai pihak (input). Kerja sama tersebut membantu wanita pengusaha untuk berinovasi dan mengembangkan usaha. Pengembangan usaha tersebut membawa mereka pada kesuksesan. Kesuksesan yang dimaksud oleh wanita pengusaha adalah kebahagiaan, dapat membahagiakan diri sendiri dan orang lain.

Berdasarkan Gambar 1, faktor eksternal sebagai input, kemudian bertransformasi menjadi sosial dan teknikal proses menghasilkan kesuksesan sebagai output. Input, process dan output merupakan sebuah sistem yang berkelanjutan. Output adalah hasil dari transformasi sistem dan lingkungan (Cummings, 2008). 
MINDSET WANITA PENGUSAHA SUKSES

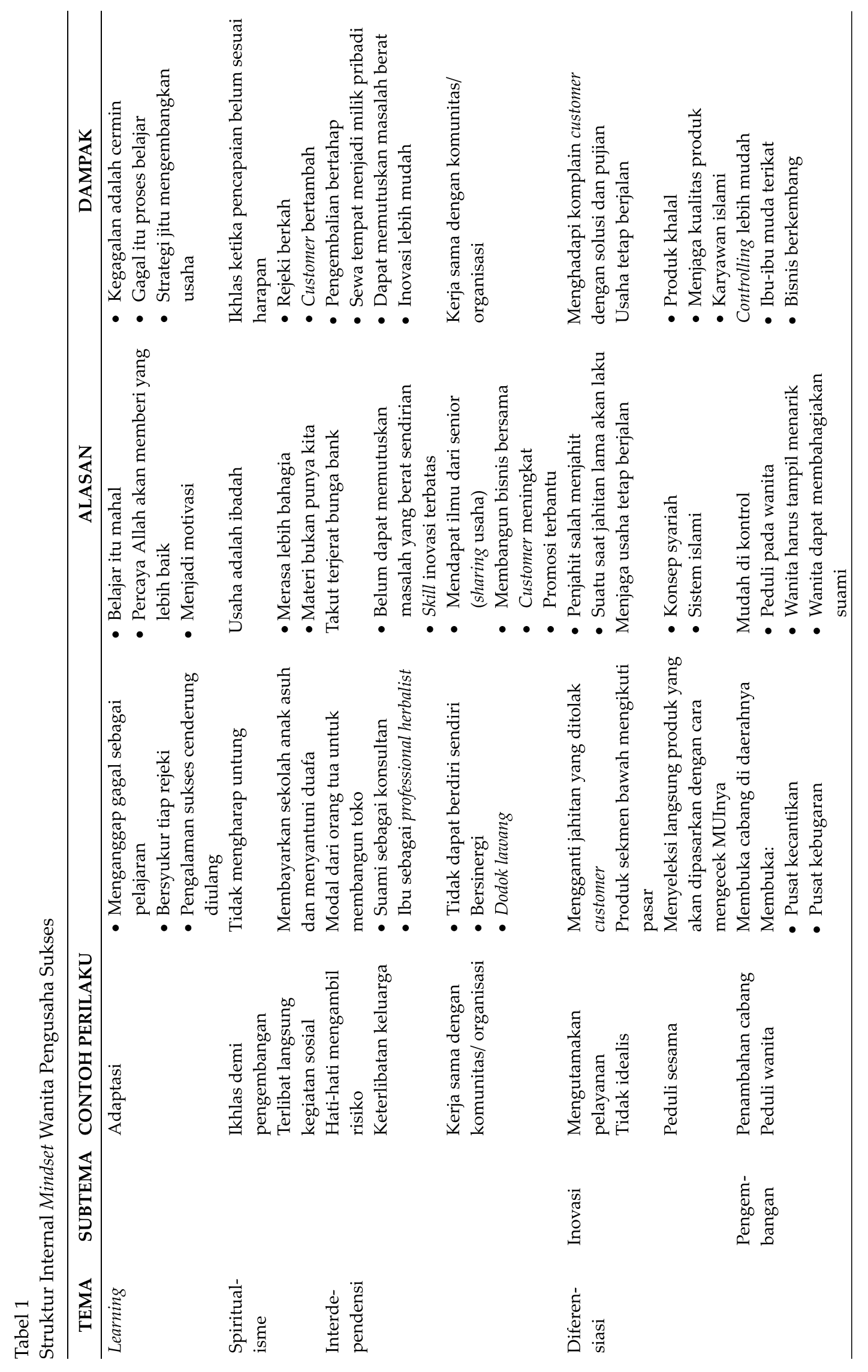


SAPUTRI \& HIMAM






\section{Diskusi}

Fujitta, Gollwitzer dan Oettigen (2007) menggambarkan mindset sebagai interaksi yang kompleks antara proses kognitif dan motivasi. Mindset juga disebut sebagai realisasi orientasi untuk selektif terhadap informasi guna mencapai tujuan. Sejalan dengan tahapan pencapaian Gollwitzer (2013), mindset wanita pengusaha terbentuk dari keinginan mereka (Fase berunding; Gollwitzer, 2013). Keingian tersebut kemudian diwujudkan dalam kegiatan wirausaha (fase planning; Gollwitzer, 2013). Berbeda dengan Gollwitzer (2013), seiring proses wirausaha, maka terbentuklah struktur internal mindset yang terdiri dari empat dimensi, yaitu; (1) learning (2) spiritualisme (3) interdependensi, dan (4) diferensiasi secara kualitas dan kuantitas. Mindset tersebut diwujudkan dalam perilaku (fase tindakan; Gollwitzer, 2013), meliputi: (1) adaptasi dari kendala usaha, pengalaman gagal dan sukses (2) kegiatan sosial (3) kerja sama, dan (4) inovasi dan pengembangan yang kemudian membawa wanita pengusaha pada kesuksesan (fase evaluasi; Gollwitzer, 2013).

Proses pembentukan struktur internal mindset sukses wanita pengusaha tidak lepas dari faktor eksternal atau lingkungan sebagai input. Hubungan input, process dan output menjelaskan sifat dan perilaku yang disebut sistem (Cummings, 2008). Menurut Cummings (2008) terdapat dua tipe lingkungan, yaitu general environment dan task environment atau industry structure. General environment meliput lingkungan sosial, teknologi dan ekonomi. Wanita pengusaha memiliki kendala dalam hal ekonomi dalam menjalani usaha. Task environment atau industry structure meliputi pengaruh; (1) keluarga, yaitu ibu, anak, suami dan mertua (2) instansi, yaitu pemerintah, komunitas dan konsultan (3) supplier power, partner dan karyawan, dan (4) ancaman, persaingan dan kompetitor. Faktor eksternal tersebut berperan sebagai input yang membantu transformasi sosial dan teknikal proses. Lingkungan mempengaruhi bagaimana performansi dan interaksi.

Cara kerja proses tersebut dapat diamati dengan sensemaking process (Weick, 2005). Sensemaking merupakan proses mengubah keadaan menjadi situasi yang lebih dipahami dengan kata-kata dan berfungsi sebagai batu loncatan pembentukan perilaku supaya berfungsi bersama sebagai titik awal mencapai tujuan (Cummings, 2008; Weick, 2005). Proses sensemaking fokus pada pengalaman yang tidak diketahui dan tidak terduga, yaitu pengalaman sebelumnya (restrospective). Pengalaman sebelumnya berfungsi sebagai sistem untuk mendapatkan pelajaran dan perilaku terbaru atau makna dari adaptasi pada koteks perubahan (Weick, 2005). Proses sensemaking Weick (2005) merupakan hubungan timbal balik antara perubahan lingkungan (echological chage) dengan aktor (enactment) untuk membuat makna dari pengalaman terdahulu (selection) dan menjaga makna tersebut (retention). Fungsi aktor adalah menciptakan perilaku untuk menata alur yang berantakan akibat pengalaman masa lalu.

Seiring proses wirausaha, wanita pengusaha menciptakan mindset learning. Sejalan dengan Weick (2005) terkait restrospective, mindset learning merupakan adaptasi dari pengalaman gagal dan sukses serta kendala-kendala yang dialami saat usaha. Kegagalan dan kendala tersebut menurut Weick (2005) merupakan ecological change yang membuat berantakan alur pencapaian tujuan. Wanita pengusaha bertemu dengan banyak kejadian dan berpotensi bertemu dengan banyak hal yang salah, termasuk kegagalan. Menang- 
gapi kegagalan, mulanya wanita pengusaha cenderung pesimis dan tidak dapat berpikir jernih sehingga ingin menutup usahanya. Setelah bertemu dengan kegagalan, dengan proses enactment, wanita pengusaha mulai melihat dan mengelompokkan kekacauan alur (Weick, 2005) akibat pengalaman gagal tersebut. Hasil dari proses enactment adalah makna, dimana wanita pengusaha melihat kegagalan sebagai pelajaran dan cermin untuk melihat perjuangan-perjuangan sebelumnya.

Proses melihat dan memberikan makna pada kegagalan yang dialami sebagai pelajaran dan cermin, merupakan makna dari proses selection (Weick, 2005). Setelah makna terbentuk melalui proses selection, proses retention bertugas mempertahankan makna yang berkaitan dengan pengalaman masa lalu (Weick, 2005), membuat wanita pengusaha lebih ikhlas dalam menjalani usaha ketika belum sesuai dengan harapan, usaha dianggap sebagai ibadah. Setelah proses retention, kemudian mendapatkan feedback identitas dari selection dan enactment maka proses memperbaiki alur yang berantakan akibat pengalaman masa lalu dengan cara melihat dan menggolongkan dapat terus berulang menjadi suatu siklus yang berkelanjutan (Weick, 2005). Feedback merupakan informasi dari perilaku nyata maupun output dari sistem. Feedback tersebut digunakan untuk menjaga sistem atau adaptasi untuk perubahan lingkungan (Cummings, 2008).

Wanita pengusaha ikhlas menjalani usaha ketika belum sesuai harapan. Keikhlasan merupakan bentuk kedekatan terhadap Allah SWT. Bentuk lain dari kedekatan dengan Allah SWT adalah keterlibatan wanita pengusaha pada kegiatan-kegiatan sosial. Mereka terlibat langsung dalam membiayai sekolah anak karyawan, menyantuni duafa dan anak asuh karena merasa materi yang dimiliki bukan sepenuhnya milik mereka. Melalui siklus retention-enactment (Weick, 2005), terciptalah perilaku sebagai strategi untuk bangkit dari kegagalan supaya usaha sesuai dengan harapan. Strategi tersebut terbentuk dari proses sensemaking yang berfungsi sebagai cara kerja yang tepat yang ditemukan melalui pembentukan alur kerja yang lebih efektif (Weick, 2005). Bentuk perilaku wanita pengusaha pada proses enachment selain terlibat kegiatan sosial agar keuntungan lebih berkah, juga menjalin kerja sama dengan banyak pihak sebagai strategi usaha.

Kerja sama tersebut kemudian diseleksi (selection) kembali untuk memberi makna berdasarkan pengalaman kerja sama yang sudah terjalin. Makna dari kerja sama adalah bersinergi. Jika hasil kerja sama baik, maka kerja sama akan terus dipertahankan (retention) dan ditingkatkan. Siklus tersebut terus berulang hingga kerja sama dapat membantu wanita pengusaha untuk berinovasi dan mengembangkan usaha. Inovasi yang merupakan bentuk dari enactment akan terus dimaknai (selection) hingga membawa wanita pengusaha mencapai tahap pengembangan usaha. Pengembangan usaha yang dilakukan dari proses enactment akan dimaknai (selection) kembali. Bentuk perilaku pengembangan yang baik akan terus dijaga dan ditingkatkan dengan proses retention.

Siklus enactment-selecton-retention akan terus berputar menciptakan perilaku hingga membawa wanita pengusaha pada kesuksesan. Siklus tersebut membantu wanita pengusaha menemukan partner usaha yang tepat yang dapat membantu inovasi terus-menerus dan membantu pengembangan usaha. Perilaku-perilaku yang terbentuk dari siklus tersebut akan menjadi strategi yang tepat untuk menuju kesuksesan usaha. Kerja sama dijalin 
dengan sistem eksternal. Sistem eksternal tersebut juga turut memfasilitasi terbentuknya mindset wanita pengusaha sukses karena menurut Weick (2005), sensemaking berhubungan dengan interaksi sosial dan komunikasi.

Mindset yang terwujud dalam perila$\mathrm{ku}$ tersebut berfungsi sebagai petunjuk dan strategi yang tepat untuk menuju kesuksesan. Kesuksesan dari hasil penelitian ini berbeda dengan hasil riset (Buttner \& Moore, 1997; Dhaliwal, 2000; Farrington, 2006; Hailemariam \& Kroon, 2014; Kanungo, 2003; Masuo, Fong \& Yanagida, 2001; Paige \& Littrel 2002), yaitu tidak hanya dilihat melalui kriteria intrinsik dan ekstrinsik. Kesuksesan menurut wanita pengusaha tidak hanya diukur dengan materi. sukses merupakan proses belajar untuk menambah ilmu terkait usaha. Kesuksesan dicapai dengan keprihatinan dalam menjalani usaha. Wanita pengusaha rela tidak menerima gaji dan tidak berfoya-foya demi kesejahteraan karyawan dan pengembangan usaha. Wanita pengusaha mengakui dirinya sukses ketika mereka berhasil membahagiakan orang lain.

Mencapai kesuksesan tidak lepas dari pengalaman sukses dan gagal serta kendala usaha yang pernah dialami. Kesuksesan dicapai wanita pengusaha dengan menciptakan mindset. Berbeda dengan mindset kewirausahaan (Hisrich, 2008), mindset spiritualisme merupakan temuan khas dalam penelitian ini yang menunjukkan culture spesifik. Culture merupakan "shared meaning" sebagai perangkat ampuh untuk membimbing dan membentuk perilaku (Robbins, 2013) untuk mencapai tujuan. Mindset spiritualisme yang ditemukan dalam penelitian ini merupakan temuan khas wanita pengusaha yang mayoritas beragama islam. Wanita pengusaha percaya bahwa mindset spiritualisme tersebut menjadi sumber kekuatan untuk menghadapi kendala, kegagalan dan kesuksesan usaha.

\section{Kesimpulan}

Penelitian ini menghasilkan beberapa temuan. Temuan inti dalam penelitian ini adalah struktur internal mindset yang terdiri atas empat dimensi, yaitu; (1) learning (2) spiritualisme (3) interdependensi dan (4) diferensiasi. Keempat dimensi mindset tersebut diwujudkan dalam perilaku seperti: (1) adaptasi dengan kendala, pengalaman gagal dan sukses (2) kegiatankegiatan sosial (3) kerja sama, dan (4) inovasi dan pengembangan usaha. Mindset yang terwujud dalam perilaku tersebut membantu wanita pengusaha mencapai kesuksesan. Mindset tersebut berfungsi sebagai petunjuk dan strategi yang tepat untuk menuju kesuksesan. Mindset dalam penelitian ini terdiri dari tiga komponen, yaitu; (1) motivasi (2) kognitif, dan (3) metakognitif.

Saran bagi wanita pengusaha hendaknya menciptakan stuktur internal mindset learning, interdependensi dan diferensiasi dalam proses usaha. Struktur internal mindset tersebut dapat membantu wanita pengusaha mencapai kesuksesan. Saran bagi peneliti selanjutnya yang tertarik dengan penelitian sejenis, dapat megembangkan penelitian ini dengan menambah jumlah wanita pengusaha sukses seperti Mooryati Soedibyo, Martha Tilaar, Dewi Motik dan lain sebagainya. Pengembangan penelitian juga dapat dilakukan dengan membandingkan mindset wanita pengusaha dengan mindset pria pengusaha. Penelitian lanjutan tersebut bertujuan menambah informasi maupun kekayaan data terkait mindset sukses antara wanita pengusaha dan pria pengusaha. 


\section{Kepustakaan}

Ahamad, I., \& Moudud-UI-Hug, S. (2013). Women entrepreneurship in Bangladesh challenges and prospects. International Journal of Innovative Research and Development, 2(7), 41-48.

Alam, S., Jani, M., \& Omar, N. (2011). An empirical study of success factors of women entrepreneurs in southern region in Malaysia. Internal Journal of Economis and Finance, 3(2), 166-175. http://dx.doi.org/10.5539/ijef.v3n2p16.

Ali, A., \& Ali, A. (2013). Motivational factors of Somali women entrepreneurs in benadir region. Journal of Sosial Sciences and Humanities, 4(1), 5972.

Ang, S., \& Dyne, L. (2008). Conceptualization of Cultural Intelligence. Diunduh dari: http://www.culturalq. com/docs/Ang\%20\&\%20Van\%20Dyne $\% 202008 \% 20$ Handbook $\% 20$ Ch $\% 201 \% 2$ 0Conceptualization\%20of\%20CQ.pdf/ tanggal 5 Juli 2014.

Badan Pusat Statistik. (2014). Persentase Penduduk menurut Provinsi dan Jenis Kelamin tahun 2009-2012: Sosial dan Kependudukan. Diunduh dari: http:// www.bps.go.id/tab_sub/view.php?kat $=1 \&$ tabel $=1 \&$ daftar $=1 \&$ id_subyek $=40 \&$ notab=1/ tanggal 13 Februari 2014 .

Badan Pusat Statistik. (2014). Penduduk 15 Tahun Ke Atas Menurut Status Pekerjaan Utama tahun 2004-2013: Sosial dan Kependudukan. Diunduh dari: http://www.bps.go.id/tab_sub/view.ph p?kat=1\&tabel=1\&daftar=1\&id_subyek $=06 \&$ notab $=3 /$ tanggal 13 Februari 2014.

Bhardwaj, G., Parashar, I., Pandey, B., \& Sahu, P. (2008). Women Entrepreneur in India: Opportunities and Challenges. Diunduh dari: http://
www.chimc.in/Volume2.1/Volume2Iss ue1/GurendraNathBhardwaj(2008).pdf / tanggal 5 Februari 2014.

Brownson, C. (2013). Fostering entrepreneurial culture: A conceptualization. European Journal of Business and Management, 5(31), 146-155.

Bruni, A., Gherrardi, S., \& Poggio, B. (2004). Entrepreneur-mentality, gender and the study of women entrepreneurs. Journal of Organizational Change Management, 17(3), 256-268.

Buttner, E. H., \& Moore, D. P. (1997). Women's organizational exodus to entrepreneurship: Self-reported motivations and correlates with success. Journal of Small Business Management, 35(1), 34-46.

Cummings, T., \& Worley, C. (2008). Organization Development and Change. Canada: Cengange Learning.

Davis, C., Lachlan, K., \& Gallardo, H. (2009). Straight Talk About Communication Research Methods ( $1^{\text {st }}$ edition). Diunduh dari: https://www. kendallhunt.com/uploadedFiles/Kend all_Hunt/Content/Higher_Education/ Uploads/Davis_Gallardo_1e_Ch8.pdf/ tanggal 15 Juli 2014.

Derera, F., Chitakunye, P., \& O'Neill, C. (2014). Entrepreneurs in south africa the impact of gender on start-up capital: A case of women. Journal of Entrepreneurship, 23(1), 95-114. http:// dx.doi.org/10.1177/0971355713513355 .

Dhaliwal, S. (2000). Entrepreneurship a learning process: the experiences of asian female entrepreneurs and women in business. Education + Training, 8, 455-452.

Farrington, R. (2006). Women entrepreneurs: how important are their perceptions?. Academy of Entrepreneurship Journal, 12(1), 1-18. 
Fujitta, K; Gollwitzer, P., \& Oettigen, G. (2007). Mindsets and preconcious open-mindedness to icidental information. Journal of Experimental Sosial Psychology, 43, 48-61.

Ganesan, R., Kaur, D., \& Maheshwari, R. (2002). Women entrepreneurs: Problems and prospects. Journal Entrepreneurship, 11(75), 75-93. http://dx.doi. org/10.1177/097135570201100105.

Gollwitzer, P. (2012). Action Phases and Mind-sets. Diunduh dari: http://www. psych.nyu.edu/gollwitzer/90Goll_Acti onPhasesMindSets.pdf/ tanggal 4 Juli 2014.

Gupta, A., \& Govindarajan, V. (2002). Cultivating a global mindset. Academy of Management Executive Journal, 16(1), 116-126.

Hailemariam, A., \& Kroon, B. (2014). How do women entrepreneurs define success. Working Papper, 1-22.

Hisrich, R., Peters, M., \& Stepherd, D. (2005). Entrepreneurship (6th Editions). Irvin: McGraw-Hill.

Hoyos, M. (2011). Entrepreneurial Success: Interplay Between Sistemic and Individual Factors Via Networking Activities. Diunduh dari: http://sbaer. uca.edu/research/icsb/2012/De\%20Hoy os\%20450.pdf\#page=1\&zoom=auto,0,7 92/ tanggal 5 Februari 2014.

Huarng, K., Tur, A., \& Yu, T. (2012). Factor affecting the success of women entrepreneurs. Int Entrep Manag Journal, 8, 487-497. http://dx.doi.org10.1007/ s11365-012-0233-4.

Javadian, G., \& Singh, R. (2012). Examining successful iranian women entrepreneurs: An exploratory study. Gender in Management: An International Journal, 27(3), 148-164.
Kanungo, R. (2003). Entrepreneurship and Innovation Models for Development. Newdelhi: Sage Publication, Inc.

Lydianingtyas, D., Zain, D., Solimun., \& Rahayu, M. (2013). The influence of cultural environment and husbands support to the success of enterpreneurship mediated by the ability to enterpreneurship and the role of government (studies on women native trader community in traditional market in jayapura). Civil and Environmental Research, 3(7), 79-97.

Masuo, D., Fong, G., Yanagida, J., \& Cabal, C. (2001). Factors associated with business and family success: A comparison of single manager and dual manager family business households. Journal of Family and Economic Issues, 22(1), 55-73.

Moustakas, C. (1994). Phenomenological Research Methods. America: Sage Publication, Inc.

Munshi, S., Munshi, A., \& Singh, V. (2011). A study on trends visible in women entrepreneur in india and globally. Journal of Asia-Pacific Business Review, 8(3), 155-166.

Paige, R., \& Littrell, M. (2002). Craft retailers' criteria for success and sssociated business strategies. Journal of Small Business Management, 40(4), 314-331.

Ragoobur, V., \& Kasseeah, H. (2012). Unveiling the profile of women entrepreneurs in the small island economy of mauritius. Interdisciplinary Journal of Contemporary Research in Business, 4(4), 437-449.

Robbins, P. Stephen. (2013). Organization Behavior 15th Edition. America: Pearson. 
Sharma, P. (2013). Women entrepreneurship development in india. Global Journal of Management and Business Studies, 3(4), 371-376.

Story, J., \& Barbuto, J. (2011). Global mindset: A construct clarification and framework. Journal of Leadership $\mathcal{E}$ Organizational Studies, 18(3), 377-384. http://dx.doi.org/10.117/1548051811404 421.

Tambunan, T. (2008). Women entrepreneurs in micro, small \& medium entreprises: Some evidence from asia developing countries. University of New South Wales at ADFA, 1-28.
Tambunan, T. (2009). Women entrepreneurs in indonesia: Their main constraints and reasons. Journal of Asia Entrepreneurship and Sustainability, 5(3), 37-51.

Weick, K. (2005). Organizing and the process of sensemaking. Organization science, 16(4), 409-421. http://dx.doi. org/10.1287/orsc.1050.0133.

Wicker, A. (1969). Attitudes versus actions: The relationship of verbal and overt behavioral responses to attitude object. Journal of Sosial Issues, 25(4), 41-78. 